\title{
Natural Gas-Oxygen Combustion in a Super-Critical Carbon Dioxide Gas Turbine Combustor
}

\author{
Ivan Komarov ${ }^{1, *}$, Daria Kharlamova $^{1}$, Bulat Makhmutov $^{1}$, Sofia Shabalova ${ }^{1}$, and Ilya Kaplanovich ${ }^{1}$ \\ ${ }^{1}$ National Research University “Moscow Power Engineering Institute”, Moscow, Russia
}

\begin{abstract}
The paper presents results for chemical kinetics of combustion process in the combustor of oxyfuel cycle super-critical carbon dioxide gas turbine based on the Allam thermodynamic cycle. The work shows deviation of the normal flame propagation velocity for the case of transition from the traditional natural gas combustion in the N2 diluent environment to the combustion at super-high pressure up to 300 bar in $\mathrm{CO} 2$ diluent. The chemical kinetics parametric study involved the Chemkin code with the GRI-Mesh 3.0 kinetic mechanism. This mechanism provides good correspondence between calculation results and test data. The CO2 and N2 diluents temperature, pressure and contents influence the flame propagation velocity and the chemical kinetics parameters in the two gas turbine types. It is demonstrated that the $\mathrm{CO} 2$ diluent slows down chemical reactions stronger than the N2 one. The flame propagation velocity in carbon dioxide is four time smaller than in the $\mathrm{N} 2$ one. In the oxy-fuel cycle combustor a pressure increase reduces the flame propagation velocity. Increase of the $\mathrm{CO} 2$ content from 60 to $79 \%$ reduces the flame propagation velocity for $65 \%$ at atmospheric pressure and for $94 \%$ at super-critical pressure. An increase of the combustor inlet mixture temperature from 300 to $1100 \mathrm{~K}$ at super-critical pressure causes the flame propagation velocity increase for $94 \%$. The flame propagation velocities compatible with the traditional gas turbines may be reached at the $\mathrm{CO} 2$ diluent content of the $\mathrm{O} 2+\mathrm{CO} 2$ mixture in the active combustion zone must be below $50 \%$.
\end{abstract}

\section{Introduction}

Transition to the environmentally friendly, low toxic and greenhouse emissions cycles is one of the most prospective directions for the hydro-carbon power production industry. The closed gas turbine cycles on super-critical carbon dioxide with organic fuel combustion in pure oxygen seem very attractive. In these terms, the Allam cycle (Figure 1) promises maximal production efficiency and nearly zero emissions [1-5].

Introduction of the Allam cycle requires solutions of a range of research problems that includes development of the power equipment analysis to operate with new heat carriers at non-traditional thermodynamic parameters.

The Allam cycle parameters of oxy-fuel combustion differ from the traditional gas turbines by the following parameters:

- The oxy-fuel cycle combustor pressure of 300 bar instead of the traditional gas turbines values below 30 bar;

- Methane is burned in the carbon dioxide environment instead of the nitrogen diluent in traditional gas turbines.

The common combustor analysis is based on the detailed description of methane combustion in air environment at pressures up to 30 bar. The analysis determines the complete fuel burnout conditions, oxygen-fuel mixture velocity at the combustor entry and the components residence time for the high temperature reaction zone. The oxy-fuel cycle combustor development involves methane oxygen combustion in the carbon dioxide environment at super-critical pressure up to 300 bar and investigation of the flow aerodynamic structure at the oxygen-fuel mixture formation and $\mathrm{CH} 4-$ O2 combustion [6-9]. This paper discloses the chemical kinetics investigation that makes a base for further 3-D simulation of the $\mathrm{CH} 4-\mathrm{O} 2-\mathrm{CO} 2$ combustion and the results that are adequate to the actual processes. Especially important is the transition from N2 to $\mathrm{CO} 2$ combined with the combustor inlet parameters increase that is related to the normal flame propagation velocity. This parameter depends upon temperature, pressure and the components contents but is not related to the combustor burner design, or the flame tube structures. The analysis results provide a conclusion on the necessity to change the combustor inlet oxygen-fuel mixture velocity and the diluent content $(\gamma-$ $\mathrm{CO} 2 /(\mathrm{CO} 2+\mathrm{O} 2))$ that provide the flame stability and complete burn-out. The combustor envelope dimensions are similar to the traditional gas turbines [10-12].

\footnotetext{
* Corresponding author: komarov vanya@bk.ru
} 


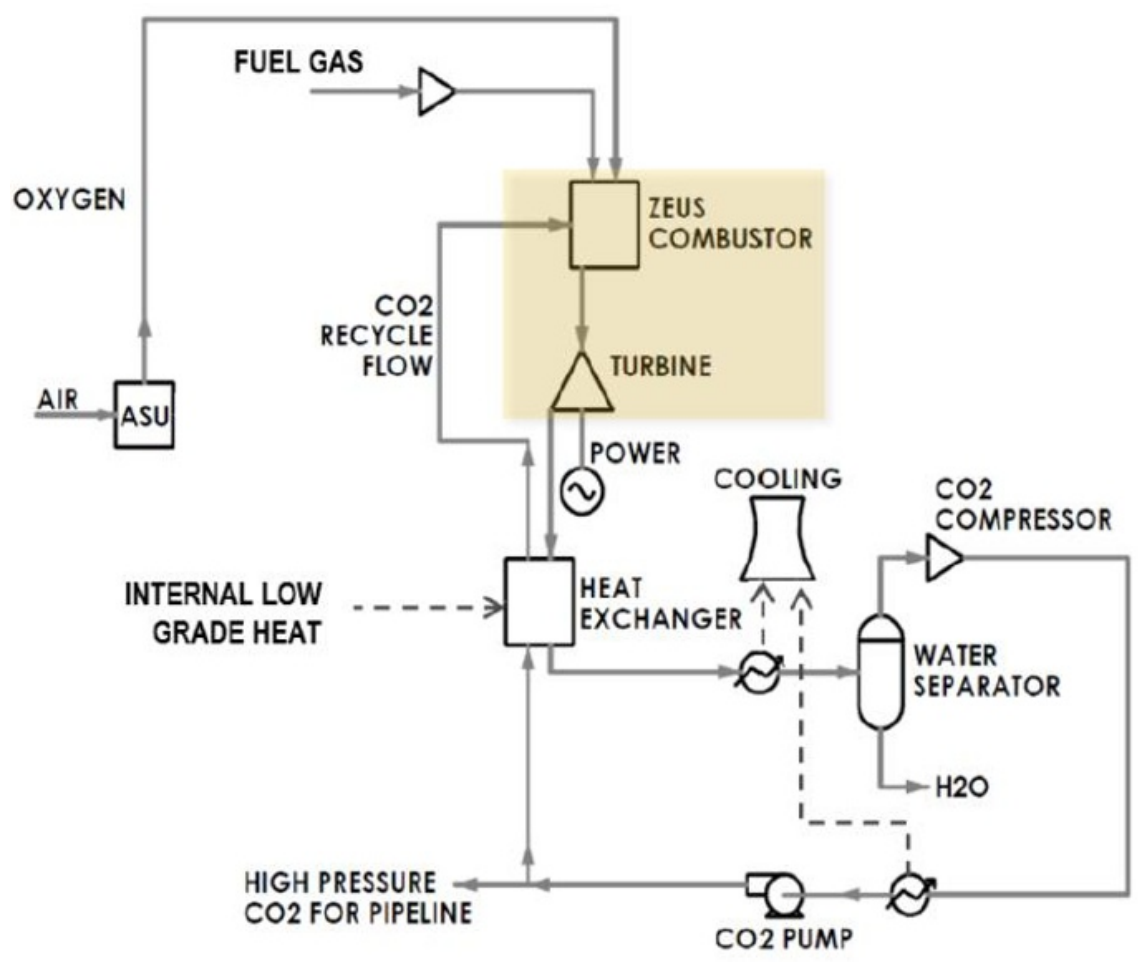

Fig. 1. Flow chart of Allam cycle on natural gas fuel.

\section{Materials and Methods}

The parametric study on influence of the diluent type and concentration upon the $\mathrm{CH} 4-\mathrm{O} 2-\mathrm{CO} 2$ and $\mathrm{CH} 4-\mathrm{O} 2-\mathrm{N} 2$ mixture combustion kinetic parameters was carried out with the Chemkin computer simulation code.

In the study were selected the following detailed kinetic mechanisms that allow calculations with numerous mixture contents and initial parameters. The following two kinetic mechanisms were considered [1317]:

- Mechanism \#1: GRI-Mesh 3.0 developed for the natural gas combustion including the chemical incomplete combustion. The mechanism basic kinetics involves 53 intermediate reaction products and 325 convertible chemical reactions of the methane transformation into complete combustion products;

- Mechanism \#2: USC II involves 325 components and 725 convertible reactions applied to a broad spectrum of combustion scripts. The USC II model was developed on the combustion mechanism GRI-Mesh 3.0, the hydrogen and carbon monoxide combustion, the fuel combustion model C3 and the complex model of ethylene and acetylene combustion. The both models include the reaction velocity data from the recent actual investigations.

The results were verified by comparison with the test data of the papers [18-20].

The results show that at atmospheric pressure the

Table 1. Summarizes input data for the chemical kinetics parametric studies on the $\mathrm{N} 2$ and $\mathrm{CO} 2$ diluents at different pressures, diluent contents and reactor inlet temperatures.

\begin{tabular}{|c|c|c|c|c|}
\hline $\begin{array}{c}\text { Analysis } \\
\text { series }\end{array}$ & $\begin{array}{c}\text { Pressure, } \\
\text { bar }\end{array}$ & $\begin{array}{c}\text { Diluent type } \\
\text { and mass content, } \gamma\end{array}$ & $\begin{array}{c}\text { Gas mixture temperature upstream } \\
\text { combustion reactor, K }\end{array}$ & $\begin{array}{c}\text { Oxidizer excess } \\
\text { coefficient }\end{array}$ \\
\hline \multicolumn{7}{|c|}{ Diluent CO2 } \\
\hline 1 & 1 & 0.60 & 300 & $0.7-1.4$ \\
\hline 2 & 1 & 0.64 & 300 & $0.7-1.4$ \\
\hline 3 & 1 & 0.68 & 300 & $0.7-1.4$ \\
\hline 4 & 1 & 0.79 & 300 & 1.0 \\
\hline 5 & $20-300$ & 0.60 & 300 & 1.0 \\
\hline 6 & $20-300$ & 0.64 & 300 & 1.0 \\
\hline 7 & $20-300$ & 0.71 & 300 & 1.0 \\
\hline 8 & $20-300$ & 0.74 & 300 & 0.7 \\
\hline 9 & $20-300$ & 0.79 & $300-1200$ & 1.4 \\
\hline \multicolumn{7}{|l|}{ Diluent N2 } \\
\hline 10 & 1 & 0.79 & 300 & 1.0 \\
\hline 11 & $20-300$ & 0.79 & $300-1200$ & \\
\hline
\end{tabular}




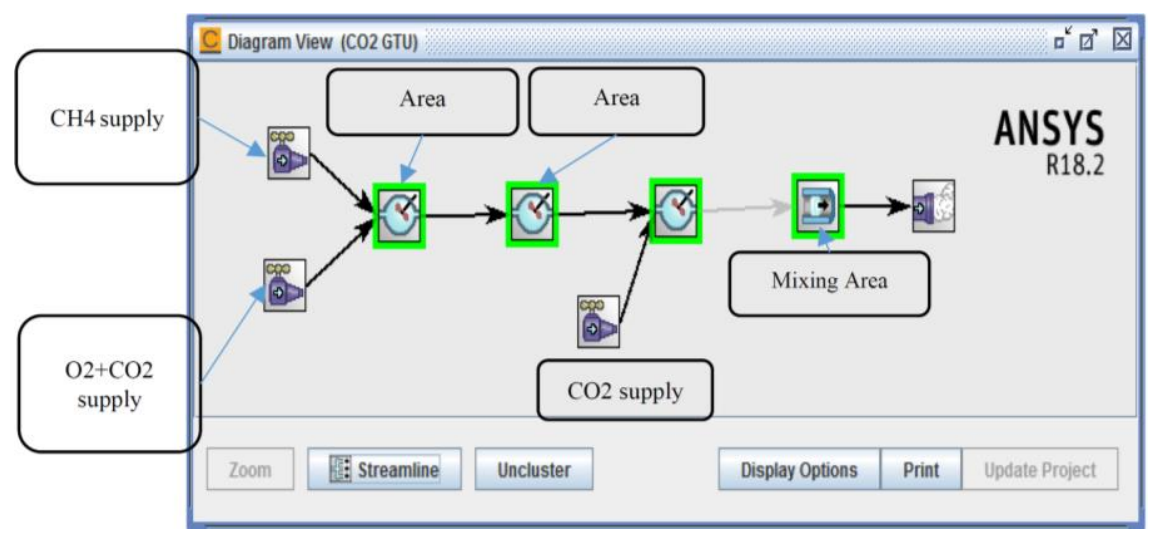

Fig. 2. Combustor structure comprised of the Chemkin reactors.

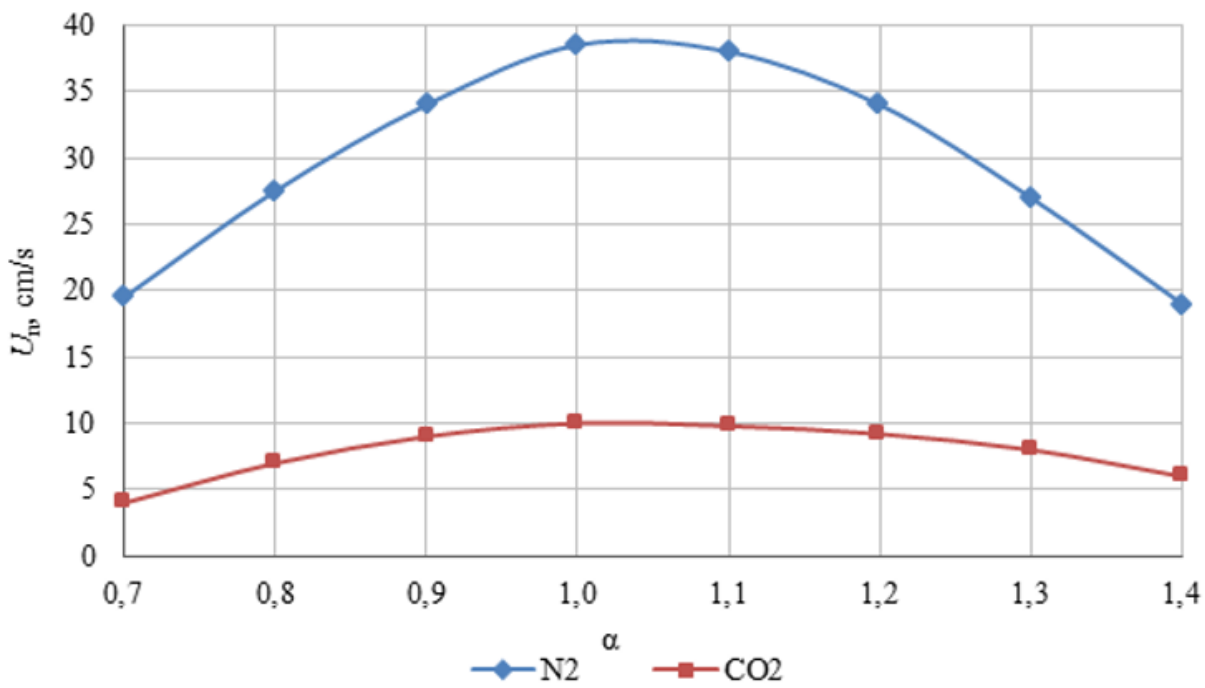

Fig. 3. Normal flame propagation velocity in the $\mathrm{N} 2$ and $\mathrm{CO} 2$ diluents $(\gamma=0.79)$ at atmospheric pressure and gas temperature $300 \mathrm{~K}$.

both detailed mechanisms demonstrate moderate deviations from the test data. At high pressure the USC II shows overrated estimations of the flame propagation velocity and the GRI-Mesh 3.0 underrates it. The GRIMesh 3.0 calculation error is below 3.5\% and the USC II One is above $6 \%$. The further calculations were carried out with the GRI-Mesh 3.0.

Figure 2 shows the combustor structure model comprised of a set of elementary reactors. The model includes the staged supply of $\mathrm{CO} 2$ diluent into the combustor. The mixture is ignited at the $\mathrm{CO} 2$ volumetric content equal to the value $\gamma$. The second $\mathrm{CO} 2$ flow cools the combustor walls, the third flow supplied to the end of active combustion zone mixes with the main flow as to reach the target temperature.

\section{Results}

Figures 3-6 show the normal flame propagation velocities in the $\mathrm{N} 2$ and $\mathrm{CO} 2$ environments at different initial values of oxygen-fuel mixture temperature and pressure, oxidizer excess and the diluent contents in diluent-oxygen mixture.

The calculation results show that the carbon dioxide is a stronger chemical reactions inhibitor than nitrogen. The maximal flame surface propagation velocity is 10 $\mathrm{cm} / \mathrm{s}$, and with the $\mathrm{N} 2$ diluent at other conditions being equal it is almost $40 \mathrm{~cm} / \mathrm{s}$. In average at the oxidizer excess coefficient from 0.7 to 1.4 the normal flame propagation velocity in the carbon dioxide environment is four times smaller.

Reduction of the $\mathrm{CO} 2$ content in its mixture with oxidizer at $\gamma$ reduction for 0.1 increases the flame propagation velocity for $2 \mathrm{~cm} / \mathrm{s}$ in average. The maximal increase occurs at the $\mathrm{CO} 2$ content reduction from 0.74 to 0.6 . In the whole range of oxidizer excess coefficients the maximal flow propagation velocity occurs at $\alpha=1$.

Pressure increase reduces the normal flame propagation velocity. The maximal reduction occurs at moderate pressure values below 70 bar. The further pressure increase also reduces $U_{\mathrm{n}}$, but in a remarkably smaller degree. 


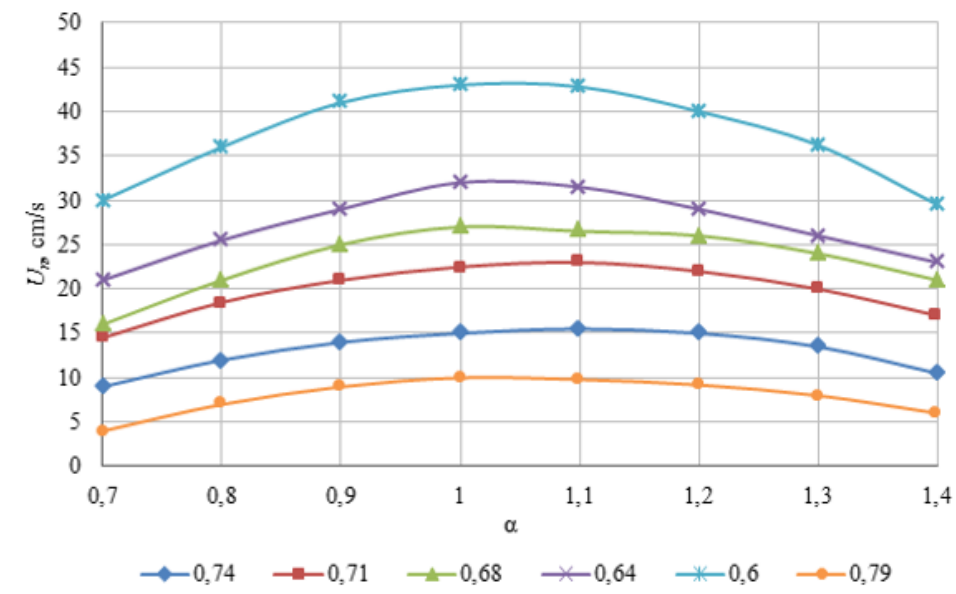

Fig. 4. Normal flame propagation velocity at different $\gamma(\mathrm{CO} 2)$ and oxidizer excess values at atmospheric pressure and gas temperature $300 \mathrm{~K}$.

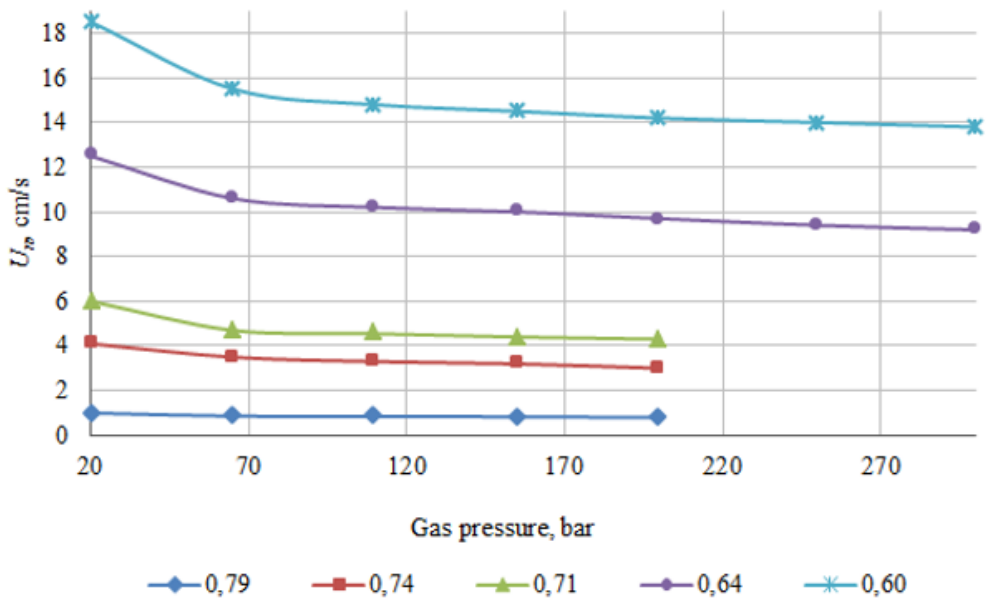

Fig. 5. Normal flame propagation velocity at different pressure and $\gamma(\mathrm{CO} 2)$ values at gas temperature $300 \mathrm{~K}$.

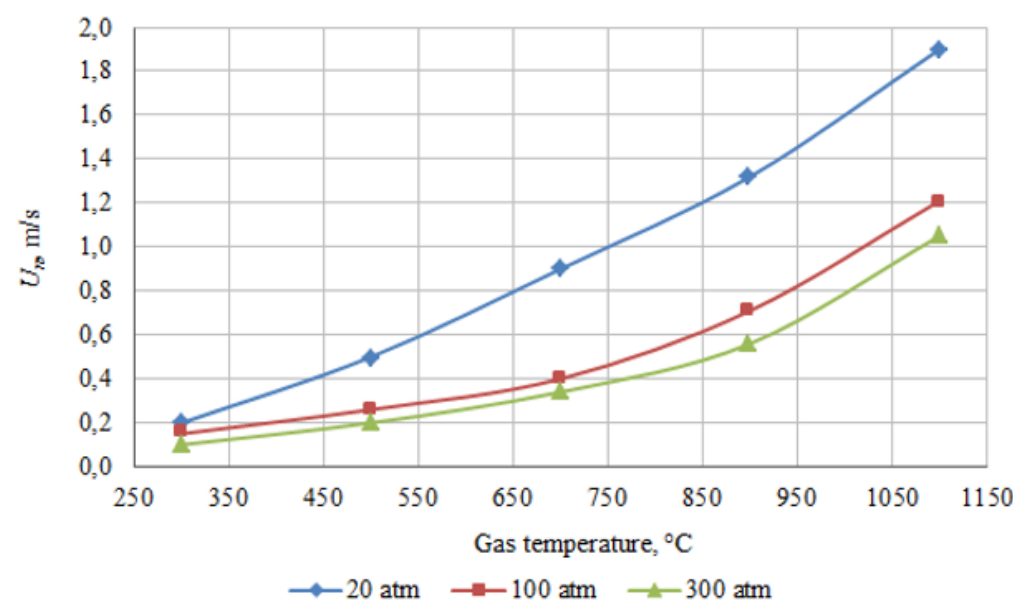

Fig. 6. Normal flame propagation velocity at in the $\mathrm{CO} 2$ diluent at different combustor inlet gas pressure and temperature $(\gamma=$ $0.71)$.

According to the Ошибка! Источник ссылки не найден. results increase of the gas mixture temperature is followed by the normal flame propagation velocity growth at all pressure values, and the growth rate is nonlinear. The temperature increase from 900 to $1100^{\circ} \mathrm{C}$ increases the velocity for average $22 \mathrm{~cm} / \mathrm{s}$. At lower mixture temperatures the similar $200^{\circ} \mathrm{C}$ temperature increase causes only a $8-10 \mathrm{~cm} / \mathrm{s}$ increase. At the initial mixture temperature $T_{0}$ convection and radiation heat transfer heats the mixture up to the ignition temperature $T_{i}$ that begins exothermal reactions and the mixture temperature grows. It is obvious that when the mixture 


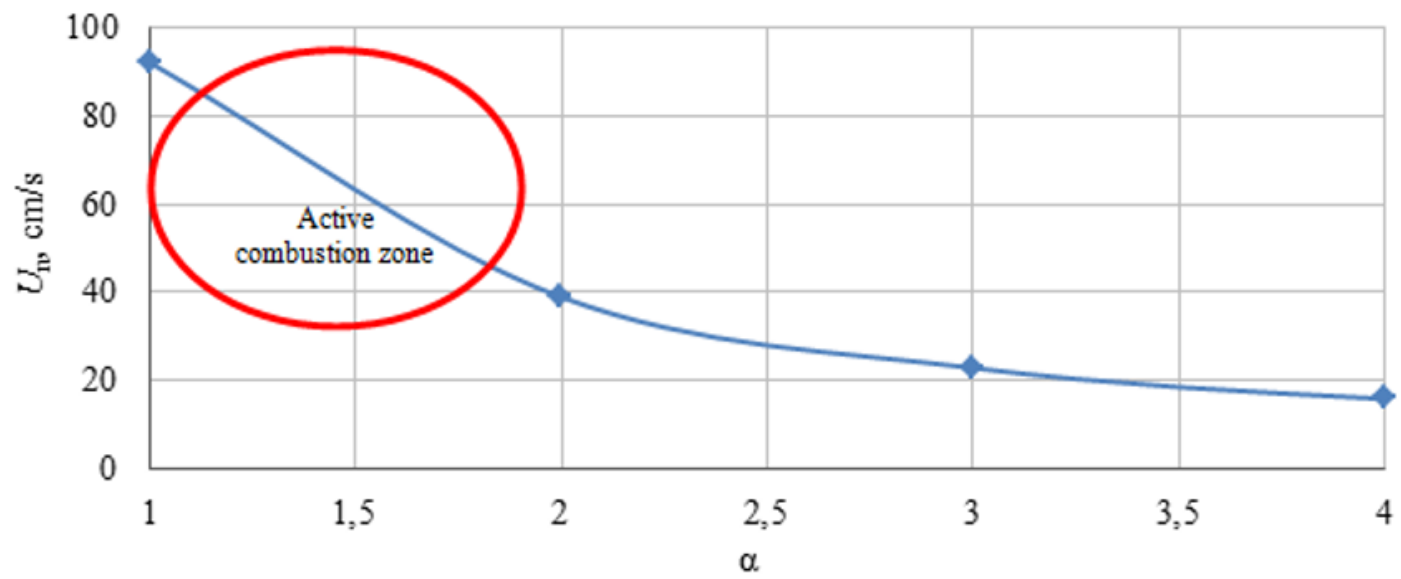

a) Gas pressure $30 \mathrm{bar}$, gas temperature $866 \mathrm{~K}$, diluent $-\mathrm{N} 2(\gamma=0.79)$

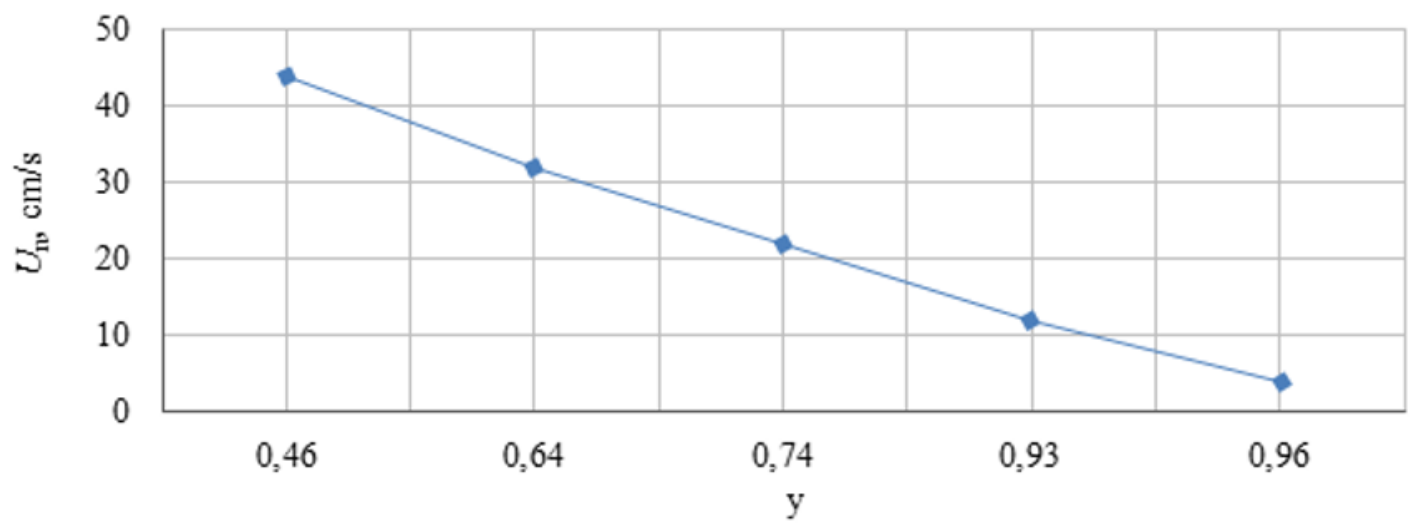

b) Gas pressure $300 \mathrm{bar}$, gas temperature $933 \mathrm{~K}$, diluent - CO2

Fig. 7. Normal flame distribution velocity in the traditional and oxy-fuel cycle gas turbines.

temperature $T_{0}$ reaches the ignition border it causes a faster mixture ignition.

Ошибка! Источник ссылки не найден.а shows the normal flame propagation velocity for a traditional gas turbines combustor, pressure $30 \mathrm{~atm}$ and $T_{\text {in }}=866 \mathrm{~K}$ that corresponds to the compressor exit at compression up to 30 bar. Ошибка! Источник ссылки не найден.b demonstrates a similar velocity relation with the $\mathrm{CO} 2$ diluent rate $\gamma$ in the oxy-fuel cycle combustor.

The Ошибка! Источник ссылки не найден.b results show that the flame propagation velocity in oxyfuel cycle combustor is near to $U_{\mathrm{n}}$ of the traditional gas turbines if the $\mathrm{CO} 2$ diluent content in the mixture is below 0.5 .

\section{Discussion}

The main research results are the following:

- The $\mathrm{CO} 2$ diluent is a stronger chemical reactions inhibitor than N2. At other conditions equal the normal flame propagation velocity in $\mathrm{CO} 2$ is four times smaller than the $\mathrm{N} 2$ diluent one, the $75 \%$ velocity reduction from 39 to $10 \mathrm{~cm} / \mathrm{s}$ at the diluent content in oxidizer $79 \%$;
- The combustor pressure increase reduces the flame propagation velocity, at the pressure increase from 20 atm up to super-critical pressure of 200 atm the reduction is $36 \%$;

- A change in the $\mathrm{CO} 2$ concentration of the diluent in the mixture with the oxidizing agent in the range of the volume content from 60 to $79 \%$ leads to a decrease in the flame propagation rate by $65 \%$ (from 42.5 to 10 $\mathrm{cm} / \mathrm{s}$ ) at atmospheric pressure and by $94 \%$ at supercritical pressure (from 14.2 to $0.8 \mathrm{~cm} / \mathrm{s}$ ).

In relation with the ballasting gas content supplied together with oxidizer at $\mathrm{CO} 2-\mathrm{O} 2$ diluent mass contents from 0.945 to 0.460 the following parameters are determined:

- The normal flame propagation velocity verifies from 7 to $45 \mathrm{~cm} / \mathrm{s}$. A $1 \%$ reduction of the diluent content in CO2-O2 mixture increases the $U_{\mathrm{n}}$ velocity for $1.4 \%$;

- The $U_{\mathrm{n}}$ amount for the natural gas combustion in the $\mathrm{O} 2$ and $\mathrm{CO} 2$ mixture is compatible with the traditional gas turbine combustors at the $\gamma$ values from 0.47 to 0.65 . This $\gamma$ range corresponds to the $\mathrm{CO} 2$ content in the $\mathrm{O} 2+\mathrm{CO} 2$ mixture in the active combustion zone below $15 \%$ of the total mass. 


\section{Conclusion}

The investigation results show the problems concerned with transition to the new diluent and higher combustor pressure. In the oxy-fuel cycle conditions $\mathrm{CO} 2$ remarkably slows the combustion process. Stable efficient methane combustion in the oxygen and carbon dioxide mixture may be reached under the following conditions:

- Carbon dioxide supply into the active combustion zone must be below $20 \%$ of its total mass flow. This flow must be split into two parts, one as a mixture with oxidizer with the $\gamma$ of $\mathrm{CO} 2-\mathrm{O} 2$ mixture below 0.5 , and second along the combustor walls for its cooling. This $\mathrm{CO} 2$ flow split allows application of the traditional gas turbine combustor recommendations;

- The gas-fuel mixture velocity in the oxy-fuel cycle combustor must be below $20-25 \mathrm{~m} / \mathrm{s}$;

Further 3-D combustion simulation may employ the GRI-Mesh 3.0 kinetic mechanism, its calculation results fit test results with errors below $3.5 \%$.

\section{Acknowledgemetns}

This study conducted by Moscow Power Engineering Institute was financially supported by the Ministry of Science and Higher Education of the Russian Federation (project No. FSWF-2020-0020).

\section{References}

[1] F. Weizhong, The research on design and technology of new high efficiency supercritical unit - a kind of cross-compound steam turbine generator unit in a manner of elevated and conventional layout, Proceedings of the 2-nd IEA CCC Workshop on Advanced Ultras-Supercritical Coal-Fired Power Plants, Rome, Italy (2014)

[2] S. Martin, B. Forrest, N. Rafati, X. Lu, J. Fetvedt, M. McGroddy, D. Freed, Progress update on the Allam cycle: commercialization of NET Power and the NET Power Demonstration Facility, Proceeedings of the 14-th Greenhouse Gas Control Technologies Conference, Melbourne, Australia (2018)

[3] A.B. Amato, P.D. Hudak, D. Carlo, D. Noble, J. Scarborough, T. Seitzman, T. Lieuwen, Methane oxy-combustion for low $\mathrm{CO} 2$ cycles: Blowoff measurements and analysis, Journal of Engineering for Gas Turbines and Power 133, 6 (2011)

[4] S. Suzuki, Y. Iwai, M. Itoh, Y. Morisawa, P. Jain, Y. Kobayashi, High pressure combustion test of gas turbine combustor for 50MWth supercritical $\mathrm{CO} 2$ demonstration power plant on Allam cycle, Proceedings of the International Gas Turbine Congress, Tokyo, Japan (2019)

[5] A. Alenezi, J.S. Kapat, Thermodynamic analysis of $\mathrm{CO} 2$ Allam cycle for concentrated solar power complemented with oxy-combustion, Proceedings of AIAA Propulsion and Energy Forum, Indianapolis, Indiana, USA (2019)

[6] I.L. Polezhaev, V. Yu, Normal flame propagation speed and analysis of the influence of system parameters on it, Thermophysics of high temperatures 43, 6, 933-942 (2005)

[7] E.L. Petersen, M. Röhrig, D.F. Davidson, R.K. Hanson, C.T. Bowman, High-pressure methane oxidation behind reflected shock waves, Proceedings of the Symposium (International) on Combustion 26, 1, 799-806 (1996)

[8] A.H. Lefebvre, Gas turbine combustion: Alternative fuels and emissions (Boca Raton: CRC Press, 557, 2010)

[9] G. Kim, Y. Kim, Y.J. Joo, Conditional moment closure for modeling combustion processes and structure of oxy-natural gas flame, Energy \& Fuels 23, 9, 4370-4377 (2009)

[10] B.T. Chorpening, K.H. Casleton, G.A. Richards, M. Woike, B. Willis, Stoichiometric oxy-fuel combustion for power cycles with $\mathrm{CO} 2$ sequestration, Proceedings of the 3-rd Joint Meeting of the US Sections of the Combustion Institute, Chicago, Illinois, USA (2003)

[11] S. Coogan, X. Gao, A. McClung, W. Sun, Evaluation of kinetic mechanisms for direct fired supercritical oxy-combustion of natural gas, Proceedings of the Turbomachinery Technical Conference and Exposition, Seoul, South Korea (2016)

[12] V.P. Zhukov, V.A. Sechenov, A.Y. Starikovskii, Spontaneous ignition of methane-air mixtures in a wide range of pressures, Combustion, Explosion and Shock Waves 39, 5, 487-495 (2003)

[13] M.D. Smooke, Reduced kinetic mechanisms and asymptotic approximations for methane-air flames: A topical volume (Berlin: SpringerVerlag, 245, 1991)

[14] N. Slavinskaya, M. Braun-Unkhoff, P. Frank, Reduced reaction mechanisms for methane and syngas combustion in gas turbines, Journal of Engineering for Gas Turbines and Power 130, 2, 021504 (2008)

[15] H. Wang, X. You, A.V. Joshi, S.G. Davis, A. Laskin, F. Egolfopoulos, C.K. Law, USC Mech Version II, High-temperature combustion reaction model of H2/CO/C1-C4 compounds (2007) [Electronic resource]. Available at: http://ignis.usc.edu/Mechanisms/USC-

Mech\%20II/ USC_Mech\%20II.htm

[16] D. Healy, D.M. Kalitan, C.J. Aul, E.L. Petersen, G. Bourque, H.J. Curran, Oxidation of C1-C5 alkane quinternary natural gas mixtures at high pressures, Energy \& Fuels 24, 3, 1521-1528 (2010)

[17] X. Gao, S. Yang, W. Sun, A global pathway selection algorithm for the reduction of detailed chemical kinetic mechanisms, Combustion and Flame, 167, 238-247 (2016)

[18] A. Frassoldati, T. Faravelli, E. Ranzi, The ignition, combustion and flame structure of carbon monoxide/hydrogen mixtures, Note 1: 
Detailed kinetic modeling of syngas combustion also in presence of nitrogen compounds, International Journal of Hydrogen Energy 32, 15, 3471-3485 (2007)

[19] W.P. Fan, Y. Gao, Y.M. Zhang, C.L. Chow, W.K. Chow, Experimental studies and modeling on flame velocity in turbulent deflagration in an open tube, Process Safety and Environmental Protection 129, 291-307 (2019)

[20] G. Gai, S. Kudriakov, B. Rogg, A. Hadjadj, E. Studer, O. Thomine, Numerical study on laminar flame velocity of hydrogen-air combustion under water spray effects, International Journal of Hydrogen Energy 44, 31, 17015-17029 (2019) 